\title{
Influences of Strength Parameters' Polymorphic Distribution on Instability Probability of Slope Based on M-C Method
}

\author{
Yi Liu',a,Ningyu Zhao ${ }^{1,2, b}$ and Kai Chen ${ }^{1, c}$ \\ 1. School of Civil Engineering, Chongqing Jiaotong University, Chongqing 400074, P.R. China \\ 2. State Key Laboratory of Mountain Bridge and Tunnel Engineering, Chongqing 400074, P.R. \\ China;
}

a5718465@qq.com, bZny2008@163.com, cchenkai6666@foxmail.com

\begin{abstract}
Keywords: landslide; Monte-Carlo method; instability probability; normal distribution; lognormal distribution
\end{abstract}

\begin{abstract}
The conventional landslide calculation is obtaining a specific stability safety factor by using limit equilibrium method or strength reduction method based on the given strength parameters of soil. Although the M-C(Monte-Carlo) method provides a path to predict instability probability of landslide, in the traditional application of M-C to calculate the probability of landslide failure, the value $c, \varphi$ of soils are considered to obey normal distribution. In fact, the value $c, \varphi$ obeys various distribution under different kinds of cases. This paper discussed the calculation of landslide failure probability of soil parameters under different distribution types. The results show that the instability probability calculated under the form of normal distribution which the value of $c, \varphi$ obeyed is lower than that under the logarithm normal distribution. The proposed method can improved the calculation accuracy of instability probability of landslide and had certain reference value for the calculation of the landslide instability probability.
\end{abstract}

\section{Introduction}

For the stability evaluation of landslides, the most commonly method is using the strength parameters of soils to calculate the safety factor based on the investigation on the test. However, under the actual conditions, the physical and mechanical parameters of soils (such as friction coefficient, cohesion, bulk density, etc.), the pore water pressure, the external load is complex, changeable, random and related ${ }^{[1]}$. The traditional evaluation results is that when the stability coefficient Fs >1,the landslide is stable, and when the stability coefficient Fs $>1$, the landslide is in danger, so the two extremes are not reasonable ${ }^{[2]}$. What more important is the instability probability of landslide is unable to give and lack of understanding of hazard control of landslide .So when evaluating the stability of landslide, it seemed reasonable to add instability probability calculation of landslide.

In the traditional landslide instability probability calculation, the influence of the landslide stability factors are a random variable, the soil parameters $c, \varphi$ is considered to obey normal distribution, but in the actual use of Monte-Carlo to calculate the probability of the landslide instability, the different types of soil parameters probability distribution will affect the calculation results of reliability index. The probability distribution of soils parameters can be divided into Bernoulli distribution series, Poisson distribution series, extreme value distribution series, central limit distribution series and the distribution series for statistical analysis. Different distribution types have a considerable impact on the calculation of the instability probability of the landslide. Therefore, in the process of calculating the probability of landslide instability, we should first 
consider the probability distribution of the soil parameters $c, \varphi$ value, and then, based on Monte Carlo (Monte-Carlo) method, calculate the probability of landslide instability.

\section{Monte-Carlo Basic Principle}

At present, there are main methods to calculate the probability of landslide instability, such as a two order matrix method, the probability moment point estimation method (also known as the Rosen blueth method), the Monte-Carlo simulation method, etc.. Because of the limitation of the (Monte-Carlo)by question is small, the convergence and limit state equation are nonlinear, the variable distribution is non normality, the applicability is strong, and the calculation program is easy to be prepared, so it is used more widely.

Monte-Carlo method is a common method for solving the practical engineering problems related to random variables by numerical simulation. The probability of the occurrence of the event can be estimated by a large number of experimental results. When the number of samples is enough, the frequency of the actual occurrence can be equated to the probability. Monte-Carlo method is based on a large number of random variables sampling, and then put it into its performance function, to determine whether the failure, so as to obtain the failure probability. For example, as for the stability coefficient of landslide, the function of the forced state and the soil structure can be expressed as:

$$
F_{s}=f(\sigma, \tau, h, w, p, \ldots)
$$

In the formula, $\sigma$ is the normal stress condition, $\tau$ is the shear stress condition, $h$ is the the terrain condition, $w$ is the ground water condition, and $p$ is of the external load condition. These parameters are random variables, most of which are subject to normal distribution or lognormal distribution.

Its performance function can be expressed as:

$$
Z=F_{s}-1
$$

The probability of failure, that is, the probability of landslide failure can be expressed as:

$$
P_{f}=P(Z<0)=P\left(F_{s}<1\right)=\int_{0}^{1} f\left(F_{s}\right) d F_{s}
$$

$f\left(F_{s}\right)$ is the probability density function of $F_{s}$.

In the actual sample calculation, the failure probability can be calculated by the following method.

$$
F_{s}=N / M
$$

In the formula, $N$ is the total times of simulation; $M$ is the emergence times under the condition of Fs $>1$

\section{Verified By an Engineering Example}

Landslide Description. The front edge height of the sliding body is $122 \sim 124 \mathrm{~m}$, the trailing edge height is $220 \mathrm{~m}$, the north and south direction (from the leading edge to the trailing edge) is about $300 \mathrm{~m}$, the width is $150 \sim 180 \mathrm{~m}$, the area is $48 \times 103 \mathrm{~m}^{2}$, the average thickness is $15 \sim 20 \mathrm{~m}$, the most thickness is $24 \mathrm{~m}$, the volume is about $674 \times 103 \mathrm{~m}^{3}$. The sliding bed bedrock is a medium weathered shale, and the sliding body is silt clay with small amount of weathered rock, and the geological section of the landslide is shown in Figure 1. 


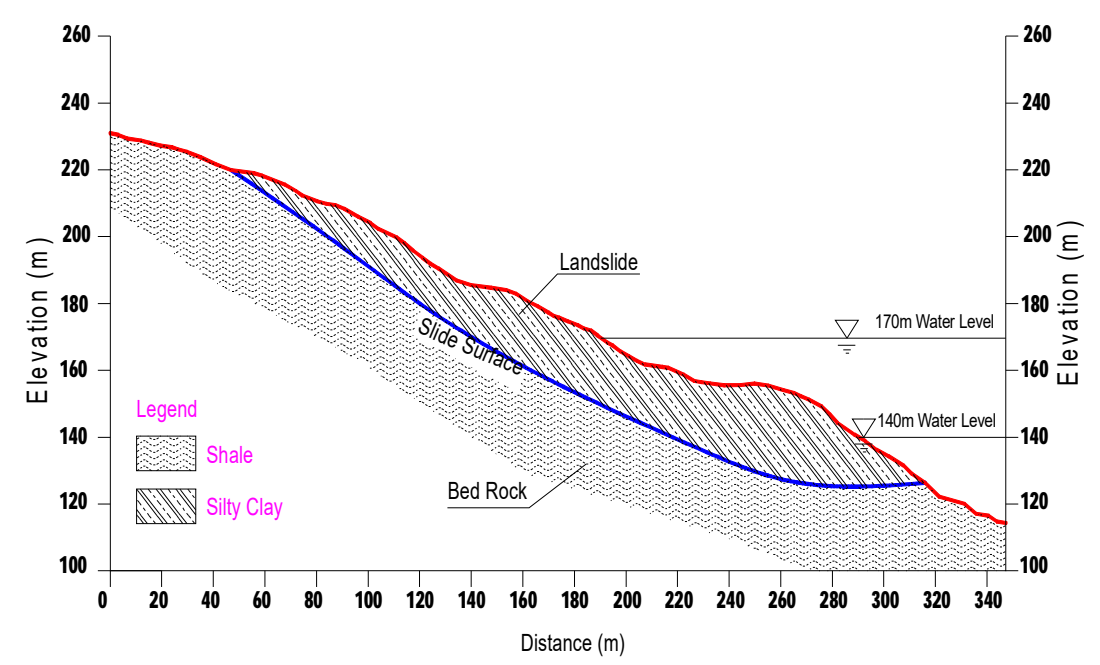

Figure 1 Geological Section

Landslide Parameters Selection. According to the landslide groups of borehole sampling indoor test and field test, to obtain the mechanical parameters $c, \varphi$ value of soil and rock of slip zone and calculating its mean value, standard deviation, coefficient of variation, coefficient of skewness (skewness ), seeing Table 1:

Table 1 mechanics parameters of soils of sliding zone

\begin{tabular}{|c|c|c|c|c|c|c|}
\hline \multicolumn{7}{|c|}{ Natural cohesive $c$} \\
\hline $\begin{array}{l}\text { Sample } \\
\text { number }\end{array}$ & $\mathrm{Min} / \mathrm{Kpa}$ & $\mathrm{Max} / \mathrm{Kpa}$ & Average/Kpa & $\sigma \quad($ Standard deviation $)$ & Coefficient of variation & Skewness \\
\hline 22 & 12.1 & 31.5 & 16 & 5.21 & 0.326 & 0.817 \\
\hline \multicolumn{7}{|c|}{ Natural internal friction angle $\varphi$} \\
\hline $\begin{array}{l}\text { Sample } \\
\text { number }\end{array}$ & $\operatorname{Min} /\left(^{0}\right)$ & $\operatorname{Max} /\left({ }^{0}\right)$ & Average / $\left({ }^{0}\right)$ & $\sigma \quad($ Standard deviation $)$ & Coefficient of variation & $\begin{array}{l}\text { skewness } \\
\text { coefficient }\end{array}$ \\
\hline 22 & 14.6 & 24.1 & 18.1 & 2.25 & 0.124 & 0.017 \\
\hline \multicolumn{7}{|c|}{ Saturated cohesive $c$} \\
\hline $\begin{array}{l}\text { Sample } \\
\text { number }\end{array}$ & $\mathrm{Min} / \mathrm{Kpa}$ & $\mathrm{Max} / \mathrm{Kpa}$ & Average /Kpa & $\sigma \quad($ Standard deviation $)$ & Coefficient of variation & $\begin{array}{l}\text { skewness } \\
\text { coefficient }\end{array}$ \\
\hline 20 & 6.8 & 25.5 & 12 & 5.22 & 0.435 & 0.741 \\
\hline \multicolumn{7}{|c|}{ Saturation internal friction angle $\varphi$} \\
\hline $\begin{array}{l}\text { Sample } \\
\text { number }\end{array}$ & $\operatorname{Min} /\left({ }^{0}\right)$ & $\operatorname{Max} /\left({ }^{0}\right)$ & Average $/\left({ }^{0}\right)$ & $\sigma \quad($ Standard deviation $)$ & Coefficient of variation & $\begin{array}{l}\text { skewness } \\
\text { coefficient }\end{array}$ \\
\hline 20 & 8.9 & 22.8 & 14.1 & 3.11 & 0.221 & 0.021 \\
\hline
\end{tabular}

The Instability Probability Calculation of The Different Distribution. For the non standard normal distribution, it can be obtained using the random variables of the standard normal distribution through linear transformation:

$$
x=\mu+\sigma x
$$

In the formula,$x$ is the standard normal distribution random variable, $\mu \sigma$ is the mean and standard deviation of the non standard normal distribution random variable $x$.

In this paper, we use Box and Muller transform method ${ }^{[10]}$, take two independent [0,1] interval uniform random number and use two yuan function conversion, and then get random variables of normal distribution by the formula5. 
The log normal distribution and normal distribution have the determination of the conversion relationship. If the random variable Y obeys the normal distribution of the mean value $\mu$ and the variance $\sigma^{2}$, through the formula $X=e^{Y}$, the X obeys the lognormal distribution.

After the corresponding treatment of $c \varphi$, the probability density of $c$ and $\varphi$ values obtained from the random 10000 groups of data are shown in Figure 2 to Figrue5.

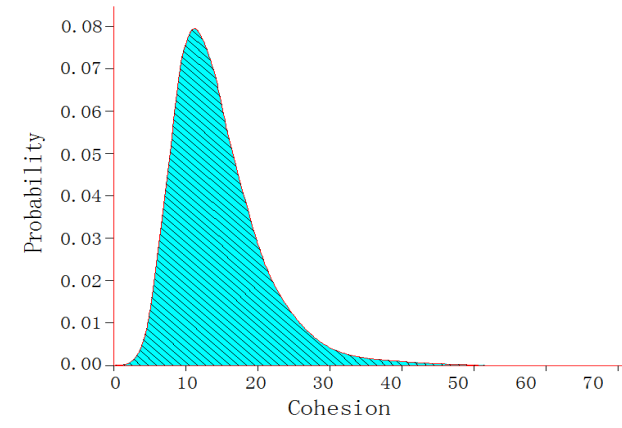

Figure 2 Probability density distribution of natural $c$

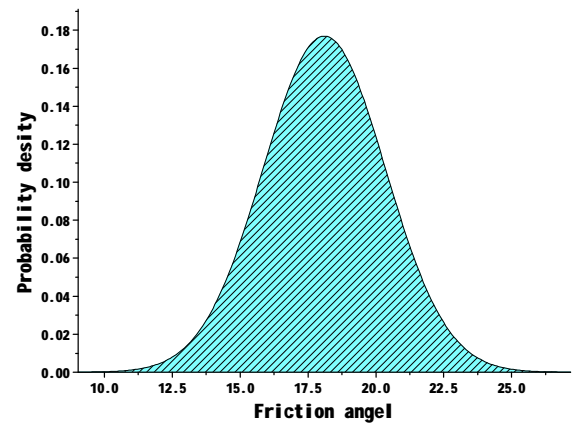

Figure 4 Probability density distribution of natural $\varphi$

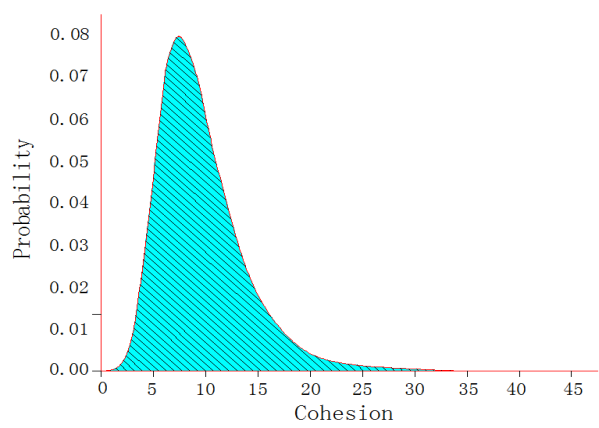

Figure 3 Probability density distribution of saturated $c$

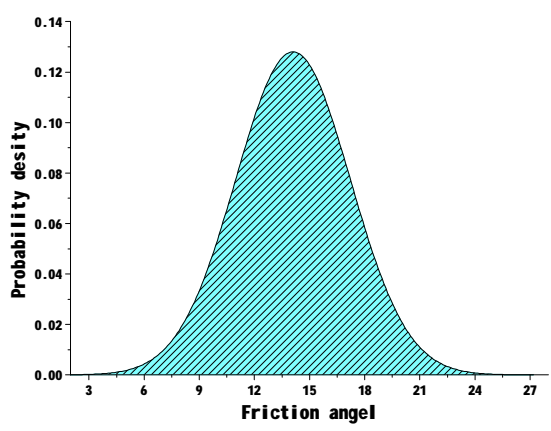

Figure 5 Probability density distribution of saturated $\varphi$

When the sliding surface is a broken line, the stability of landslide is calculated by transfer coefficient method (pushing transfer method), and the stability of the following four conditions is considered:

Case1: 140m water level + weight;Case2: 170m water level + weight;

Case3: 140m water level + weight+heavy rain;Case4: 170m water level + weight+heavy rain;

According to the 10000 sets of $c$ and $\varphi$ values, by random sampling and put into the formula of transfer coefficient method ,the stability coefficient of the landslide can be determined, and the probability of failure and loss can be calculated by the formula 2 ,seeing in tabel 2 .

Table 2 instability probability of different distribution forms

\begin{tabular}{|c|c|c|c|c|}
\hline Case & $\begin{array}{l}\text { Stability coefficient } \\
\text { mean }\left(F_{s}\right)\end{array}$ & $\begin{array}{l}\text { Standard deviation of stability } \\
\text { coefficient }\left(\sigma_{F}\right)\end{array}$ & $\begin{array}{l}\text { Coefficient of } \\
\text { variation } \\
(\delta)\end{array}$ & $\begin{array}{c}\text { Instability } \\
\text { probability } \\
\left(P_{F}\right)\end{array}$ \\
\hline Case1 & 1.21453 & 0.146231 & 0.120401 & 0.072335 \\
\hline Case2 & 1.17601 & 0.178955 & 0.152171 & 0.158121 \\
\hline Case 3 & 1.14213 & 0.178421 & 0.156217 & 0.218563 \\
\hline Case4 & 1.07852 & 0.184600 & 0.171160 & 0.342232 \\
\hline
\end{tabular}


Calculation of Instability Probability of The Same Distribution. If you do not consider the special distribution pattern of the soils parameter, cohesion and friction angle are considered to obey distribution, meanwhile, using transformation method Box and Muller proposed, processing of slip soil parameters, then probability density distribution chart of natural $c$ value and saturation $c$ are shown in Figure 6, 7:

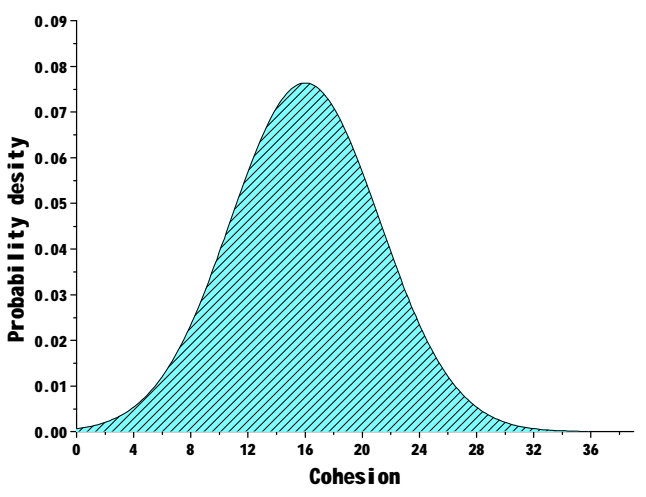

Figure6 Probability density distribution of natural $c$

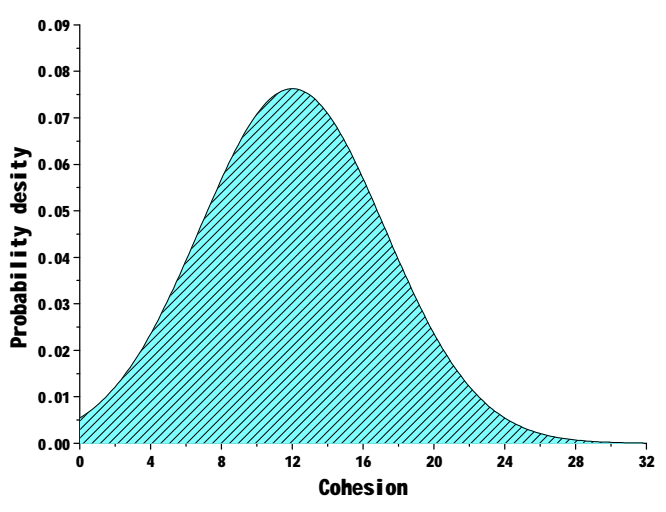

Figure7 Probability density distribution of saturated $c$

In the same way, the stability of the landslide can be calculated by the transfer coefficient method when the sliding surface is a broken line, and the probability of landslide failure is calculated,seeing at tabel3:

Tabe 3. Instability probability of the same distribution

\begin{tabular}{|c|c|c|c|c|}
\hline Case & $\begin{array}{l}\text { Stability coefficient } \\
\text { mean }\left(F_{s}\right)\end{array}$ & $\begin{array}{c}\text { Standard deviation of } \\
\text { stability coefficient }\left(\sigma_{F}\right)\end{array}$ & $\begin{array}{l}\text { Coefficient of } \\
\text { variation }(\delta)\end{array}$ & $\begin{array}{l}\text { Instability probability } \\
\qquad\left(P_{F}\right)\end{array}$ \\
\hline Case1 & 1.18233 & 0.15866 & 0.134193 & 0.092667 \\
\hline Case2 & 1.15987 & 0.192563 & 0.166021 & 0.176233 \\
\hline Case 3 & 1.13653 & 0.194432 & 0.171075 & 0.239656 \\
\hline Case4 & 0.98563 & 0.203445 & 0.194233 & 0.407455 \\
\hline
\end{tabular}

Comparative Analysis of Two Cases. Through the calculation of the two kinds of different situations, the instability probability of the two cases is quite different. The results show that the same distribution of the instability probability is higher than that of different distributions, seeing in tabel4.

Table 4 nstability probability of the two distribution forms

\begin{tabular}{cccc}
\hline Case & $\begin{array}{c}\text { Instability probability of } \\
\text { different distribution }\end{array}$ & $\begin{array}{c}\text { Instability probability of } \\
\text { same distribution }\end{array}$ & Relative percentage (\%) \\
\hline Case1 & 0.072335 & 0.092667 & 28.10811 \\
\hline Case2 & 0.158121 & 0.176233 & 11.45452 \\
\hline Case3 & 0.218563 & 0.239656 & 19.050764 \\
\hline Case4 & 0.342232 & 0.407455 & 12 \\
\hline
\end{tabular}

From table 3 and figure 8, We can draw that if using form of the normal distribution, the instability probability calculated was larger than that of the different distribution . The reasons may be that when the coefficient of variation of mechanical parameters of soils $>30 \%$ and the skewness 
coefficient $>0.025$, if using the normal distribution, it may lead distribution of soils parameter to be larger, even produce negative number (as truncated part shown in Figure 6, 7). If the log normal distribution is used, the distribution of the parameters of the rock mass is relatively concentrated, and no negative number is generated (Figure. 2, 3). If The $c$ and $\varphi$ values of the soils parameters turn small, the stability coefficient decreases and the instability probability becomes larger.

According to the relative percentage of Table 4, the relative percentage of the instability probability between different distribution forms and the same distribution form ranges from $10 \%$ to $25 \%$, which shows that the error generated ranges from $10 \%$ to $25 \%$, when $c$ and $\varphi$ values of soils mass under this case are in different distributions. And with the previous research results ranged from $20 \%$ to $30 \%$, the result is smaller, the reason may be that when $c$ and $\varphi$ values obey what Distribution, considering coefficient of variation and skewness coefficients $c$ and $\varphi$ values, and the coefficient of variation of $\varphi$ value $<30 \%$ and the coefficient of skewness $<0.025$, so there's no change the distribution pattern, but only changes distribution form $c$ value, resulting in low error.

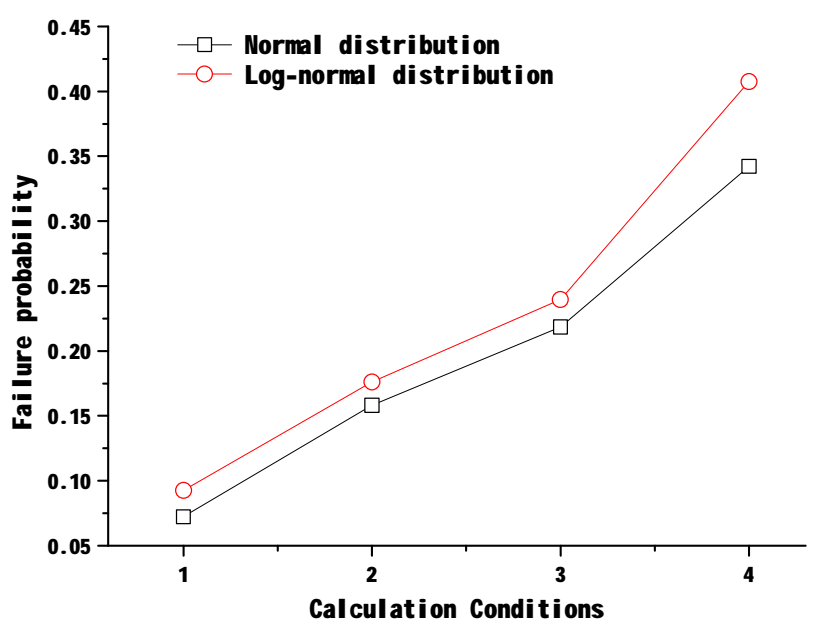

Figure 8 Comparison of the probability instability in the two distribution forms

\section{Conclusions}

In this paper,based on Monte Carlo (Monte-Carlo) method, the instability probability of a landslide is calculated, and the traditional method of landslide instability is made up; the landslide is stable, under the condition of Fs $>1$ and the landslide is in danger, under the condition of Fs < 1 ,which has certain reference value and significance to engineering practice.

1. Through the calculation of landslide instability probability, we can drawed that the stability coefficient of the landslide was 0.98563 , the instability probability was over $40 \%$, the possibility of instability was much high, under the case of $170 \mathrm{~m}$ water level dropped to $140 \mathrm{~m}$ water level + weight + heavy rain.

2.If the distribution of the parameters of soils was considered, the instability probability of landslide calculated by the normal distribution and lognormal distribution was relatively lower than that of only using normal distribution.

3. Through the process of $c$ and $\varphi$ value by normal distribution and logarithmic normal distribution, if considered the use of distribution form of variation coefficient and coefficient skewness of $c$ and $\varphi$ value, the error of two instability probability ranged from $10 \%$ to $25 \%$. 


\section{Acknowledgments}

The authors are grateful to the National Natural Science Foundation of China (Project No: 51608081 ) and the Foundation of State Key Laboratory of Mountain Bridge and Tunnel Engineering (CQSLBF-Y16-18) for the financial support for this research project.

\section{References}

[1] Wang, Y., Z. Cao and S. Au, Efficient Monte Carlo Simulation of parameter sensitivity in probabilistic slope stability analysis. 2010. 37(7-8): p. 1015-1022.

[2] Tobutt, D.C., Monte Carlo Simulation methods for slope stability. 1982. 8(2): p. 199-208.

[3] Tamimi, S., B. Amadei and D.M. Frangopol, Monte Carlo simulation of rock slope reliability. 1989. 33(6): p. 1495-1505.

[4] Park, H., T.R. West and I. Woo, Probabilistic analysis of rock slope stability and random properties of discontinuity parameters, Interstate Highway 40, Western North Carolina, USA. 2005. 79(3-4): p. 230-250.

[5] Peng, M., et al., Slope safety evaluation by integrating multi-source monitoring information. 2014. 49(0): p. 65-74.

[6] Zhou, G., et al., Spatial probabilistic modeling of slope failure using an integrated GIS Monte Carlo simulation approach. 2003. 68(3-4): p. 373-386.

[7] Wang, Y., Uncertain parameter sensitivity in Monte Carlo Simulation by sample reassembling. 2012. 46(0): p. 39-47.

[8] YAN Chun-feng,LIU Dong-yan,ZHANG Jian-hui.et a1.The Susceptibility analysis of reliability for probabilitydistribution types of parameters in strength criterion.Chinese Journal of Rock Mechanics and Engineering,1999.18(1):36-39.

[9] Lodahl MR, Brødbæk KT, Sørensen CS. "Applications of reliability-based calibration of partial factors for design of railway embankments," Proceedings of the 5th international young geotechnical engineers conference. Paris, France; pp. 23-26. 2013.

[10]Duncan J M. "State of the art: limit equilibrium and finite element analysis of slopes," Journal of geotechnical engineering, v 122, n 7, pp: 577-596, 1996.

[11]Bishop, A. W. "The use of slip circle in stability analysis of slopes." Geotechnique, v 5,n 1, pp 7-17, 1955.

[12]Take, W.A., Bolton, M.D., Wong, P.C.P. and Yeung, F.J. "Evaluation of landslide triggering mechanisms in model fill slopes", Landslides, v 1, pp. 173-184, 2004. 